\title{
Restoring certainty
}

\author{
Danièle Moyal-Sharrock
}

\begin{abstract}
This paper addresses the objections, Genia Schönbaumsfeld makes in The Illusion of Doubt, to my view of hinge certainty as a 'certainty', as nonepistemic, nonpropositional and animal. It also addresses her (related) dissatisfaction with Wittgenstein's notion of 'the groundlessness of our believing'.
\end{abstract}

\section{Wittgenstein and the Incoherence of Radical Scepticism}

Genia Schönbaumsfeld's overarching aim in The Illusion of Doubt is to defend the thesis that radical scepticism is an illusion. She does this by attempting to dispel the engrained notion that radical scepticism poses a real problem for epistemology, and therefore that it needs solving. Her position is that radical scepticism is 'an apparent claim (or set of claims) that one cannot "refute" - i.e. show to be false - as it never adds up to a genuine, substantial position in the first place' and so there is 'in the end, no 'global' sceptical scenario that requires a solution' $(2016,1)$. This approach - which I share and have myself defended ${ }^{1}-$ is inspired by Wittgenstein's On Certainty.

The threat of radical scepticism has needlessly exercised epistemologists for centuries. It has also managed to seduce some Wittgensteinians, like Stanley Cavell, for whom scepticism is an existential truth, and according to whom Wittgenstein thought as much: 'one misses the drive of Wittgenstein if one is not ... sufficiently open to the threat of scepticism (i.e. to the skeptic in oneself); or if one takes Wittgenstein ... to deny the truth of scepticism' (1979, 47). However, pace Cavell, Wittgenstein saw no truth in scepticism²; rather the opposite: he debunked radical scepticism. Indeed, it is enlightened by Wittgenstein's insights, particularly in On Certainty, that hinge epistemologists like Genia Schönbaumsfeld, Duncan Pritchard, Annalisa Coliva and I, have been able to see through the untenability of radical scepticism. Rather than rehearse Schönbaumsfeld's excellent Wittgenstein-inspired arguments to defuse the sceptical illusion, I will, in this paper, address her objections to the way I believe On Certainty takes us to the untenability of radical scepticism; that is, her objections to my view of hinge certainty as a 'certainty', and as nonepistemic ${ }^{3}$, nonpropositional and animal. I will also address her (related) dissatisfaction with Wittgenstein's notion of 'the groundlessness of our believing'. To the possible objection that: 'as long as we both get to the end - which is the untenability of radical scepticism - why bother scrutinising the means?' I would reply that this would not be a philosophically serious objection. Moreover, arguing about the (non)propositionality and the (non)epistemic nature of hinge certainty is not a mere

\footnotetext{
${ }^{1}$ See especially Moyal-Sharrock $(2002 ; 2003 ; 2004 ; 2016 ; 2017)$.

${ }^{2}$ See Moyal-Sharrock (2017a).

${ }^{3}$ I mark a distinction in my use of the terms 'epistemic' to mean 'related to knowledge' and 'epistemological' to mean 'related to the branch in philosophy we call "epistemology"'. So that to speak of 'Hinge Epistemology' is to say that 'hinges' (or hinge certainties) have a role to play in epistemology but does not imply that hinges are epistemic.
} 
exegetical or terminological exercise whose conclusion leaves the result unaffected; the nonpropositionality and nonepistemic nature of hinges is vital to the success of Wittgenstein's conceptual elimination of radical scepticism. In addition, recognising the nonpropositional and nonepistemic nature of basic certainty is crucially important to admitting 'the animal' in epistemology, and thereby getting rid of the 'propositional assumption't that riddles epistemology, philosophy generally, and the cognitive sciences. I will argue that Schönbaumsfeld's successful grasp of Wittgenstein's achievement in On Certainty is needlessly side-tracked, though not derailed, by her insistence on the propositional nature of hinge certainty to the detriment of its jointly enactive and grammatical nature.

In Chapter 4 - 'The Incoherence of Global Validation' - Schönbaumsfeld fleshes out Wittgenstein's now familiar insight that, as she puts it, 'unless something is taken for granted, neither knowledge nor doubt is logically possible' (2016, 107), and so radical scepticism is incoherent. In Wittgenstein's words: 'A doubt that doubted everything would not be a doubt' (OC 450); 'If you tried to doubt everything you would not get as far as doubting anything. The game of doubting itself presupposes certainty' (OC 115; see also OC 369-70). The bone of contention is what Wittgenstein means by 'certainty' here. On my view, the most basic certainty without which the game of doubting cannot even begin is (what Wittgenstein calls) grammar $^{5}$; for, doubting requires meaningful discourse, and meaningful discourse requires grammar. And so the sceptic's so-called radical doubt depends on certainty - the certainty of grammar $^{6}$ (or bounds of sense) - for its very conception or formulation. It turns out that radical doubt is not sustainable at all - inside the study or out - and this, not for pragmatic, but for conceptual reasons. For Wittgenstein, so-called radical doubt is not doubt at all but only doubt-behaviour? .

\footnotetext{
${ }^{4}$ An expression I owe to Britt Harrison (2013) to refer to the misguided belief that propositions are indispensable to our grasp of the world.

${ }^{5}$ What Wittgenstein means by 'grammar' is both similar to and different from what we usually mean by grammar. 'By grammatical rule I understand every rule that relates to the use of a language' (VOW 303). For him, grammar is 'a preparation for description, just as fixing a unit of length is a preparation for measuring'; so that 'A rod has a length' is as much a preparation for description (e.g. 'This rod is 3 feet long') as the grammatical rule to use 'were' and not 'are' in some contexts is a preparation for our intelligible use of language. Wittgenstein is simply more liberal than grammarians as to what he will count as grammar: 'Everything that's required for comparing the proposition with the facts belongs to grammar. That is, all the requirements for understanding. (All the requirements for sense.)' (BT 38). So grammar consists of the conditions of intelligibility of a language. It is the conventionallyestablished basis on which we can make sense: 'Grammar consists of conventions' (PG 138), keeping in mind that conventions here are not due to a concerted consensus, but to an unconcerted agreement in practice. Now if grammar includes '[a]ll the requirements for sense', it must then also include rules such as 'There exist people other than myself'. For isn't that a requisite underpinning of sense - a preparation for such descriptions as 'There are twenty of us in this room' or 'Vietnam's population is 96.5 million'?'.

${ }^{6}$ And of course grammar must be embedded in a form of life, which is rooted in 'regular ways of living'. For the concept of following a rule implies the concept of a community of rule-followers sharing the 'common behaviour of mankind' (PI 206) (see, for example, Malcolm 1986c, 156; and specifically contra Chomsky, see Moyal-Sharrock (2017c).

${ }^{7}$ 'Doubting has certain characteristic manifestations, but they are only characteristic of it in particular circumstances. If someone said that he doubted the existence of his hands, kept looking at them from all sides, tried to make sure it wasn't 'all done by mirrors', etc., we should not be sure whether we
} 
That Wittgenstein's argument is a knock-down argument against radical doubt should be so obvious as to preclude the need for further argument. The reason it hasn't, I suggest, is that conceivability (or imaginability) is taken to be sufficient for possibility by most philosophers; so that sci-fi scenarios, such as the brain-in-a-vat scenario, are viewed by most epistemologists as viable possibilities that must be contended with and argued against rather than dismissed as what Michael Williams (2017) rightly calls 'fairy-tale imaginings'. Hinge epistemology breaks away from this habit and sometimes explicitly argues against it $^{8}$.

Although generally in agreement as to the incoherence of radical scepticism, hinge epistemologists differ as to the characterization of what I like to call 'hinges' or 'hinge certainties'. As Schönbaumsfeld indicates, hinge epistemologists can be broadly divided in two camps on this, neither of which she finds promising: 'a "quasi-epistemic" reading which seeks to assimilate Wittgenstein's proposal to more epistemological views'; and 'a nonepistemic, "quasi-pragmatic" conception [which] ... equates "hinges" with a type of "animal" certainty' (2016, 108). I belong to the second camp9. At this point, I'll briefly summarize my conception of 'hinge certainty' so as to have a clear view of Schönbaumsfeld's target.

On my view, what philosophers have traditionally called 'basic beliefs' cannot, on pain of infinite regress, themselves be propositional beliefs. They are really animal or unreflective ways of acting which can only be intelligibly articulated for heuristic purposes (e.g., philosophical elucidation or pedagogical instruction). When thus articulated, what we get are not propositions, but expressions of rules of grammar (or bounds of sense). It is grammar that lies at the bottom of all our language-games; and grammar is of course embedded in human life. So that what philosophers like Descartes and Moore, as also most epistemologists today, put forward as propositions susceptible of falsification, and thereby of scepticism, are in fact heuristic formulations of certainties (e.g. 'Most human beings have hands'; 'Here / This is a hand') whose status is logical or grammatical, and whose only occurrence qua certainty is in action - that is: in what we say (e.g. 'I'll wash my hands') and in what we do (e.g. we wash our hands). This revolutionary view of basic certainty as both enacted and grammatical is precisely what makes for the genius of Wittgenstein's hinge epistemology: his dissolution of radical scepticism. And so we must stop thinking of our basic certainties as empirical propositions - as is the traditional practice of epistemology - or even as 'hinge propositions' - as is more recently done by most hinge epistemologists - and think of them as bounds of sense or expressions of rules of grammar.

\section{The (non)propositionality of hinges}

ought to call that doubting. We might describe his way of behaving as like the behaviour of doubt, but his game would not be ours.' (OC 255)

${ }^{8}$ As mentioned at the start of this paper, one of Schönbaumsfeld's aims in this book is to show the untenability of this position. See also her (2017) and (2019). See also Baumann (2019). For references to my own work on this, see note 1 .

${ }^{9}$ For discussions of the similarities and differences of both camps, see Pritchard (2012, 2017), Coliva (2010), Moyal-Sharrock (2016; 2017b). 
Despite referring to them as 'hinge propositions', Schönbaumsfeld seems to agree that we have here to do with expressions of rules of grammar: 'one might say that "hinge propositions" are an attempt to articulate the logical enabling conditions that allow our epistemic practices to operate, and without which even our words could not mean anything' (2016, 116). She also explicitly agrees with me that 'what stands fast for us reveals itself in what we say and do, and is only articulated in, say, radical sceptical contexts, where someone is questioning what we ordinarily take for granted ${ }^{\prime 10}(2016,118)$, but is wrong to then add that this would imply that I take hinges to be inexpressible $(2016,118)$. Obviously it does not: if I take hinges to be articulable in some circumstances, they are not everywhere inexpressible. As I have often clarified, I take the sensical expression of hinges to be limited to heuristic contexts (such as philosophical elucidation or pedagogical instruction). She is right, however, that it implies my taking hinges to be nonpropositional - with which she disagrees on the grounds that Wittgenstein calls them 'propositions' in several passages of On Certainty. Indeed he does; but this does not prevent him from clearly coming to realize that they are not propositions:

Giving grounds, however, justifying the evidence, comes to an end; - but the end is not certain propositions striking us immediately as true, i.e. it is not a kind of seeing on our part; it is our acting, which lies at the bottom of the language-game. (OC 204)

Because there are passages in On Certainty that back Schönbaumsfeld's decision to retain propositionality and others that back my rejecting it, the matter cannot be settled by a mere show of passages; it must be bolstered by more substantive argument. Indeed, I have argued elsewhere that we must go beyond Wittgenstein's deliberative and heuristic uses of some of the terms in On Certainty (such as 'proposition', 'know' or 'trust') to see where he ends up - that is, what he ultimately thinks about using such terms or concepts to describe the kind of certainty in question here. Some passages formulate his ultimate insights clearly enough; for example, OC 204 (above) as regards 'proposition'; or this, as regards 'know':

I should like to say: Moore does not know what he asserts he knows, but it stands fast for him, as also for me; regarding it as absolutely solid is part of our method of doubt and enquiry. (OC 151)

It might be asked, however, what the criterion is by which one should treat these passages as ultimate and others as merely deliberative. I suggest that the decisive test for accepting the overriding perspicuity of some passages over others is their coherence with their consistent and meaningful contribution to - Wittgenstein's groundbreaking account of hinge certainty: the account which puts an end to the regress problem of basic beliefs and to the coherence of radical scepticism. According to that criterion, terminological red herrings notwithstanding, we can see that everything 'speaks for' Wittgenstein's excluding hinge

\footnotetext{
${ }^{10} \mathrm{I}$ am more inclusive as to the heuristic contexts in which hinges can be articulated (e.g., teaching a child 'People die').
} 
certainty from being a proposition or a judgment. For, what would be gained by retaining propositionality, other than a return to the standard view of basic beliefs as propositions, and therefore a return to square one in our attempts to solve the regress problem? If what Wittgenstein was doing in On Certainty was to claim that our basic beliefs are propositions, why bother? He would merely be repeating what philosophers before him have been saying for centuries, all the while deploring an unsolvable regress. Only through maintaining the nonpropositionality of hinges can we do full justice to Wittgenstein's radical recognition that in the beginning is the deed, acting, and not inner beliefs or thoughts, not basic propositions. And, as will be clarified in the next section, to also speak of the grammaticality of hinges is simply to categorise these ways of acting as basic and logically requisite to the languagegames of our human form of life and our various forms of human life. So, to the possible further question of why one interpretation of On Certainty - however coherent - should be held as a/the correct interpretation, the answer would be: see whether that interpretation shows On Certainty to have achieved something unprecedented and valuable (such as dissolving radical scepticism); something that the interpreter could not, lest s/he be credited with the genius of the achievement, have conceived.

If it is crucial to Wittgenstein's account that, in Schönbaumsfeld's words, 'what stands fast for us reveals itself in what we say and do' $(2016,118)$, and that any explicit formulation of them within a non-heuristic language-game sounds nonsensical, then what is the point of calling it propositional? And if it is also crucial to Wittgenstein's account that what stands fast for us are 'logical enabling conditions' $(2016,128)$ (rules of grammar), what is the point of calling these 'propositions'? Moreover, a sufficient reason for not calling hinges 'propositions' is that truth-evaluability is the hallmark of propositions ${ }^{11}$, and hinges - by dint of being expressions of rules of grammar - are not susceptible of truth or falsity ${ }^{12}$ : 'If the true is what is grounded, then the ground is not true nor yet false' (OC 205). On one hand, Schönbaumsfeld insists on maintaining a propositional view of hinges; on the other, she sees them as 'logical enabling conditions rather than ordinary empirical propositions' $(2016,128)$; conditions that reveal themselves in what we say and do $(2016,118)$. So I fail to see what kind of 'proposition' they can be. Moreover, I don't see any argument against nonpropositionality in The Illusion of Doubt other than Wittgenstein sometimes using the term 'proposition'.

\section{The enactive nature of hinges}

This brings me to Schönbaumsfeld's objection to my view that 'our basic beliefs are a knowhow, and that this know-how is logical - that it is necessary to our making sense' (MoyalSharrock 2004, 173). She finds this 'a very odd conception. For in what sense is being able to sit on a chair, drive a car, use one's hands, move one's body, a manifestation of a grammatical

\footnotetext{
${ }^{11}$ If one needed reminding, here is an elegant formulation of this by Charles Travis: 'a proposition is the content of a truth-evaluable attitude. It is a way of exposing oneself to risk of error which one escapes or succumbs to solely in things being as they are' $(2011,183)$.

12 'We can draw the distinction between hypothesis and grammatical rule by means of the words "true" or "false" on the one hand, and "practical" and "impractical" on the other. The words "practical" and "impractical" characterize rules. A rule is not true or false.' (AWL 70)
} 
rule? This either sounds like a category mistake or renders the distinction between 'grammar' and 'know-how' void' (2016, 120-21). I wish Schönbaumsfeld would have engaged with, or even mentioned, my preemptive clarification of this possible objection (Moyal-Sharrock 2004, 52-53). A first answer to the objection that hinges cannot both express rules of grammar and be a way of acting is Wittgenstein's enactive notion of rules: a rule is an enabler ${ }^{13}$; to follow a rule is not to make a judgment, but to make a move ${ }^{14}$. My other answer to the objection is that this dual aspect of hinges simply reflects the dual perspective from which Wittgenstein is elucidating our basic certainty in On Certainty. The first is phenomenological: here, he is describing what it is like to be basically certain - and the answer is that it is like an unreflective way of acting or attitude, a know-how or reflex action (like taking hold of my towel (OC 510)). My certainty that 'This is my friend CS standing in front of me' manifests itself in my speaking to him directly, without a moment's hesitation that is, without first questioning and ascertaining that it is really him; that he really is a person or a human being; that human beings can speak; that human beings exist etc. Similarly. my using some words (e.g. 'table' 'tree' or 'hand') unhesitatingly also shows the unreflective mastery of a technique or know-how that characterizes hinge certainty. The second perspective might be called categorial or epistemological: here, Wittgenstein is describing how basic certainties fit in our epistemological categories, or what Duncan Pritchard calls 'the structure of rational evaluation' $(2018,2)$ - and, from this perspective, they are seen to have a nonepistemic, grammatico-logical status.

These two descriptions seem incompatible but are not; they are complementary in elucidating the phenomenological nature and philosophical status of our hinge certainties. For Wittgenstein, underpinning knowledge are certainties 'in action' that can be verbally rendered for heuristic purposes and whose conceptual analysis uncovers their function in our epistemological trees as unjustifiable rules of grammar. I might add that Schönbaumsfeld's objection that hinges cannot be seen as both expressing rules of grammar and being a way of acting seems odd to me in that she herself takes them to be 'logical enabling conditions' $(2016,128)$ that reveal themselves in what we say and do $(2016,118)$. And inasmuch as she agrees that 'we can, for heuristic reasons, on occasion articulate the logical enabling conditions that make our epistemic practices possible' $(2016,122)$ - what is that if not articulating the rules of grammar that enable our basic ways of speaking and acting?

\footnotetext{
${ }^{13}$ When we learn rules, we do not learn a content but a technique, a skill, a mastery - how to proceed. Indeed, in the Remarks on the Foundations of Mathematics, Wittgenstein notes the dispensability of propositions in arithmetic, stressing the similarity of calculating to gestures, and of the teaching of arithmetic to a training: 'Might we not do arithmetic without having the idea of uttering arithmetical propositions, and without ever having been struck by the similarity between a multiplication and a proposition? Should we not shake our heads, though, when someone shewed us a multiplication done wrong, as we do when someone tells us it is raining, if it is not raining? -- Yes; and here is a point of connection. But we also make gestures to stop our dog, e.g. when he behaves as we do not wish. We are used to saying "2 times 2 is 4", and the verb "is" makes this into a proposition, and apparently establishes a close kinship with everything that we call a "proposition". Whereas it is a matter only of a very superficial relationship' (RFM III 4).

14 'A rule is best described as being like a garden path in which you are trained to walk, and which is convenient. You are taught arithmetic by a process of training, and this becomes one of the paths in which you walk' (AWL 155).
} 
Schönbaumsfeld not only questions the intelligibility of my view of certainty as both grammatical and a way of acting, she denies $(2016,123 \mathrm{n} 21 ; 120)$ - contra McGinn (1989, 160), Coliva (2010) and Moyal-Sharrock (2004) - that certainty can be thought of as an attitude at all: as she contends, 'in ordinary circumstances, I don't have any particular doxastic attitude towards my hands - I just use them' (2016, 122-23); in fact, 'it is misleading to speak of an "attitude" here at all' $(2016,123)$, doxastic or otherwise. I suggest that her resistance betrays a reflective twist in her understanding of 'attitude' - a twist which it needn't have, as made clear by the nonreflective nature of the various attitudinal stances Wittgenstein uses in On Certainty to characterize hinge certainty. He describes it as a 'taking hold'; a regarding something as absolutely solid or as 'standing fast' for us. These metaphors are deliberately selected to emphasize the nonreflective, immediate, nonpropositional attitude which he wants to contrast with our standard view of certainty as a propositional attitude:

It is just like directly taking hold of something, as I take hold of my towel without having doubts. (OC 510)

And yet this direct taking-hold corresponds to a sureness, not to a knowing. (OC 511)

Instead of 'I know...', couldn't Moore have said: 'It stands fast for me that ...'? And further: 'It stands fast for me and many others... (OC 116)

I should like to say: Moore does not know what he asserts he knows, but it stands fast for him, as also for me; regarding it as absolutely solid is part of our method of doubt and inquiry. (OC 151)

Such attitudinal descriptions of certainty clearly render Wittgenstein's efforts to draw a crucial difference between traditional views of basic beliefs and his own enactive view: 'I want to say: it's not that on some points men know the truth with perfect certainty. No: perfect certainty is only a matter of their attitude' (OC 404; my emphasis). In opposition to our traditional way of conceiving of basic beliefs, he wants to make clear that basic certainty is an unreflective way of acting ${ }^{15}$ - 'It is our acting, which lies at the bottom of the languagegame' (OC 204) - not a tacit belief; and that it is not rational or irrational but arational or animal: 'I want to conceive it ['this certainty' (OC 358)] as something that lies beyond being justified or unjustified; as it were, as something animal' (OC 359). The hinge certainty verbalised as: 'I have a body' is a disposition of a living creature which manifests itself in her

\footnotetext{
${ }^{15}$ In Last Writings on the Philosophy of Psychology, Wittgenstein writes: 'Don't think of being certain as a mental state, a kind of feeling, or some such thing. The important thing about certainty is the way one behaves...' (LW II, p 21) / Ask not "What goes on in us when we are certain-?", but "How does it show?"' (LW II, p. 21) [see PI, p. 225: 'Ask, not: "What goes on in us when we are certain that...?" - but: How is 'the certainty that this is the case' manifested in human action?'].
} 
acting in the certainty of having a body ${ }^{16}$ : that is, she feeds, washes, scratches, dresses, photographs herself; she complains of having aches and pains; and she says things like 'I've got goose pumps all over' or 'I need to go to the gym'. There is nothing premeditated or reflective in the basic acting or attitude in question; it has the unhesitating fluidity of animal behaviour. Remember Wittgenstein's aim in On Certainty:

I want to regard man here as an animal; as a primitive being to which one grants instinct but not ratiocination. As a creature in a primitive state. Any logic good enough for a primitive means of communication needs no apology from us. (OC 475)

And in order to do this - to regard man as an animal - Wittgenstein has to confront and uproot an overly reverent view of reason:

Reason - I feel like saying - presents itself to us as the gauge par excellence against which everything that we do, all our language games, measure and judge themselves. - We may say: we are so exclusively preoccupied by contemplating a yardstick that we can't allow our gaze to rest on certain phenomena or patterns. We are used, as it were, to 'dismissing' these as irrational, as corresponding to a low state of intelligence, etc. The yardstick rivets our attention and keeps distancing us from these phenomena, as it were making us look beyond. (CE p. 389)

What On Certainty shows is that our distrust of the arational and our reliance on reason are excessive. Reason does not go all the way down: at the substratum of our thought is a logic that is animal - which meants, it is instinctual or nonreflective and therefore, obviously, nonpropositional.

\section{Hinges as certainty}

Schönbaumsfeld also objects to my use of the concepts of 'certainty' and 'trust' to characterise what Wittgenstein is trying to describe; and particularly to my use of the expression 'objective certainty' to distinguish basic certainty from 'subjective certainty'. She argues that if there were such a thing as 'objective certainty', there would have to be such a thing as 'objective uncertainty': 'For, if (in ordinary circumstances) my sitting on a chair allegedly shows my objective certainty about there being a chair to sit on, there ought to be some action that shows my objective uncertainty' (2016, 119). Schönbaumsfeld's objection to calling Wittgenstein's 'certainty' a certainty wrongly relies on the absence of the assumed dichotomy: certainty / uncertainty. In fact, she concedes that I do give hinge certainty 'an opposite pole': pathology; on my view, anyone who, in ordinary circumstances, lacked the hinge certainty

\footnotetext{
${ }^{16}$ When asleep or unconscious, this certainty remains a disposition, but becomes occurrent in any normal use she makes of her body - e.g., in her eating, running, her not attempting to walk through walls as if she were a disembodied ghost.
} 
that there was a chair to sit on would be prey, not to uncertainty but to madness (cf. OC 257). However, this view does not originate with me, it is Wittgenstein's. Inasmuch as Wittgensteinian certainty is grammatical or logical, its opposite pole cannot be uncertainty, but nonsense.

Calling our basic assurance a 'certainty' does not suggest or imply the possibility of uncertainty but 'removes uncertainty from it', as Wittgenstein writes in the Remarks on the Foundations of Mathematics ${ }^{17}$ : 'To accept a proposition as unshakably certain - I want to say - means to use it as a grammatical rule: this removes uncertainty from it' (RFM III: 39). This does not leave the concept of hinge certainty empty - without friction, as it were; for, as Wittgenstein repeatedly illustrates: where the opposite poles of epistemic certainty are uncertainty, mistake or doubt, the opposite pole of hinge certainty is nonsense or madness. If I say in earnest and nonfiguratively: 'I am not sure that there is anyone but me in this room' (when there are in fact others), I would not - in spite of the words 'I am not sure' - be displaying uncertainty, but madness. We can only understand someone's doubt, in ordinary cases, that there is a chair to sit on (or that 'Here is a hand'; or that 'I/they have a body') as constituting a pathological problem. In other words, hinge certainty (or what is here referred to in the following passage as what is 'objectively certain') is a logical certainty:

With the word 'certain' we express complete conviction, the total absence of doubt, and thereby we seek to convince other people. That is subjective certainty.

But when is something objectively certain? When a mistake is not possible. But what kind of possibility is that? Mustn't mistake be logically excluded? (OC 194)

I don't see Wittgenstein rejecting the concept of certainty here, but finessing it. He is rejecting subjective certainty but looking for something that is objectively certain, which he defines here as something that logically excludes mistake. In fact, I have long since given up using the expression 'objective certainty' because I felt a new term was needed to unambiguously render the logical exclusion of mistake that Wittgenstein was after - using 'hinge certainty' instead. Schönbaumsfeld's argument should not be affected by this change of terminology as, insofar as we cannot speak of 'uncertainty' she objects to my claiming that we are here in the presence of any kind of certainty.

Here again I must disagree: hinge certainty is a kind of certainty. Not only does Wittgenstein call it that - (e.g., 'If you tried to doubt everything you would not get as far as doubting anything. The game of doubting itself presupposes certainty' (OC 115)) - but his use of it is not, as Schönbaumsfeld contends, categorially alien to other uses of 'certainty' or indeed to uses of belief, trust and faith. We speak of 'belief in', 'trust' and 'faith' as doxastic attitudes ${ }^{18}$ and hinge certainty resembles these in being nonpropositional attitudes; but also

\footnotetext{
${ }^{17}$ Compiled of notes written mostly between 1937-44.

${ }^{18}$ As John Bishop (2016) indicates, there is no single 'established' terminology for different models of faith. A characterisation of the principal models of faith and its connections with trust and belief would include both propositional and nonpropositional models: for example: the 'belief' model: faith as belief that, say, God exists (where the object of belief is a certain proposition); the 'trust' model: faith as believing in (in the sense of trusting in), say God, (where the object of belief or trust is not a
} 
extends from them in that, in the case of hinge certainty, something not 'standing fast' for someone does not result in uncertainty but in their being prey to nonsense or pathology.

Nor does Wittgenstein reject the use of 'trust'. To Schönbaumsfeld's objection that the word 'trust' in OC $509^{19}$ is due to a bad translation, there are several other passages in $\mathrm{On}$ Certainty where the translation is unequivocal - of which the following, where 'certainty' is also used:

Must I not begin to trust [trauen] somewhere? That is to say: somewhere I must begin with not-doubting; and that is not, so to speak, hasty but excusable: it is part of judging. (OC 150)

If I make an experiment I do not doubt the existence of the apparatus before my eyes. I have plenty of doubts, but not that. If I do a calculation I believe, without any doubts, that the figures on the paper aren't switching of their own accord, and I also trust [vertraue] my memory the whole time, and trust it [vertraue] without any reservation. The certainty [Sicherheit] here is the same as that of my never having been on the moon. (OC 337)

The game of doubting itself presupposes certainty [Gewissheit]. (OC 115)

Schönbaumsfeld may believe that "'hinges" are best not conceived as certainties ... at all' (2017, 108), but evidently Wittgenstein did not share this view. Granted, he struggles to find the right words to describe our basic assurance, but the ones he does contemplate and end up using are concepts that are susceptible of both epistemic and nonepistemic; propositional as well as nonpropositional use: concepts like certainty, belief and trust. Those three he does not reject. The concept that is not thus susceptible - i.e. knowledge - he rejects in the very first passage of On Certainty: 'If you do know that here is one hand, we'll grant you all the rest'; and goes on rejecting it throughout.

\section{5. 'The groundlessness of our believing'}

Schönbaumsfeld's rejection of terms like certainty and trust may betray an insensitivity to Wittgenstein's struggle to conceptualise the nonepistemic nature of our basic certainties. This may be the reason she also finds Wittgenstein's use of the expression 'the groundlessness of our believing' objectionable. She finds it 'not felicitous' $(2016,115)$ or, as she elsewhere puts it 'rather misleading' $(2016 \mathrm{~b}, 441 \mathrm{n} 14)$.

For 'groundlessness' is itself an epistemic notion which implies that there could - or ought to - be grounds, although in fact there are none, whereas what

proposition, but God 'himself'); the 'doxastic venture' model: faith as practical commitment beyond the evidence to one's belief that, say, God exists.

${ }^{19}$ 'I really want to say that a language-game is only possible if one trusts something (I did not say "can trust something")' (OC 509). In German: 'Ich will eigentlich sagen, dass ein Sprachspiel nur moeglich ist, wenn man sich auf etwas verlasst. (Ich habe nicht gesacht "auf etwas verlassen kann".)' 
Wittgenstein is really trying to say is that it is logically impossible for there to be any, and that the absence of the possibility of 'global validation' is therefore not to be viewed as a lack or as an epistemic shortcoming. $(2016,115)$

When Wittgenstein - and some of us in suit - use the notion of groundlessness, far from it denoting a failing or limitation, it denotes a certainty so robust, so anchored, so unquestionable that it is not built on the back of justification or grounds. It characterizes the rock solidity, the 'hard rock' (OC 99) that makes our spades turn and allows us to 'stand fast' (OC 152). The concept of groundlessness is important and necessary in that it crucially underlines the absence of grounds - that is: of reasoning or justification at the foundational level. It does not mark an absence where there ought to be a presence (i.e. grounds); it marks an absence where a presence (i.e. grounds) has always been wrongly assumed. Wittgenstein is urging Moore and, by extension, all philosophers, to stop assuming that basic certainty is grounded.

When he writes: 'The difficulty is to realize the groundlessness of our believing' (OC 166), Wittgenstein is well aware of the difficulty of making himself understood - that is, of using epistemic concepts to elucidate something that is nonepistemic. And this goes, not only for 'groundlessness', but also for certainty, belief or trust which he uses to name or describe a kind of assurance that is nonepistemic. He asks, for instance: 'can one talk of belief here (I mean as in 'religious belief', not surmise)? All psychological terms merely distract us from the thing that really matters' (OC 459). This shows Wittgenstein contemplating calling basic certainty a belief - a belief-in, mind you, not a belief that (this is what is meant by 'religious belief, not surmise') - but he's afraid that even this sounds too psychological. Similarly, when he uses terms like certainty and its cognates to describe our basic assurance, he is also afraid of not hitting the mark, of being misunderstood: 'I want to say: The physical game is just as certain as the arithmetical. But this can be misunderstood. My remark is a logical and not a psychological one' (OC 447). Not psychological or epistemic (OC 511), but logical. Schönbaumsfeld allows for that distinction when applied to knowledge $(2017,116)$, but not to certainty or trust.

In speaking of 'the groundlessness of our believing', Wittgenstein wants to stress that reasons don't go all the way down. That in the beginning is the deed rather than the word (be it proposition or reason), returns us to the unimpeded fluidity of our animal natures. When he writes that, upon meeting a human being ' $[\mathrm{m}] \mathrm{y}$ attitude towards him is an attitude towards a soul. I am not of the opinion that he has a soul' (PI, p. 178), Wittgenstein means to say that there are no grounds that I entertain to ensure that a human being stands before me; the certainty here is visceral, animal, unmediated. It shows itself in my attitude, in how I act or am disposed to act. Looking for grounds here would be a sign of pathology. This for me shows, better than any philosophical argument, the vital, default, ongoing groundlessness in our lives and the consequent incoherence of scepticism.

The point is to get rid of the obstacles that have impeded our understanding of the incoherence of radical scepticism, and seeing our basic certainties as propositions fares high on the list. As for using the term 'certainty' (and, for clarity: 'hinge certainty') to refer to what Wittgenstein meant to replace tacit beliefs with, I can't think of a better term. And I don't see an alternative offered in The Illusion of Doubt. 
References

Baumann, P. 2019. Brains in Vat? Don't Bother! Episteme, 16, 2 (2019) 186-199.

Bishop, J. 2016. 'Faith' in Stanford Encyclopedia of Philosophy. https://plato.stanford.edu/entries/faith/

Coliva, A. 2010. Moore and Wittgenstein: Scepticism, Certainty, and Common Sense. Basingstoke, UK: Palgrave Macmillan.

Harrison, B. 2013. The Epistemology of Know-how (PhD thesis, University of Hertfordshire).

Malcolm, N. 1986. Nothing is Hidden: Wittgenstein's Criticism of his Early Thought. (Oxford: Basic Blackwell)

McGinn, M. 1989. Sense and Certainty (Oxford: Blackwell).

Moyal-Sharrock

2002. 'The Third Wittgenstein \& the Category Mistake of Philosophical Scepticism' in Wittgenstein and the Future of Philosophy. A Reassessment after 50 years, edited by R. Haller \& K. Puhl (Vienna: oeb\&hpt, 2002), 293-305.

2003. Logic in Action: Wittgenstein's Logical Pragmatism and the Impotence of Scepticism Philosophical Investigations 26:2 (April 2003), 125-148.

2004/2007. Understanding Wittgenstein's On Certainty (Basingstoke: Palgrave Macmillan).

2016. 'The Animal in Epistemology: Wittgenstein's Enactivist Solution to the Problem of Regress' in Hinge Epistemology, eds A. Coliva \& D. Moyal-Sharrock. (Brill, 24-47).

2017a. 'Too Cavellian a Wittgenstein: Wittgenstein's Certainty, Cavell's Scepticism' in Wittgenstein and Modernism, ed. Anat Matar (London: Bloomsbury), 92-112.

2017b. 'Knowledge and Certainty' in Blackwell Companion to Wittgenstein, eds H.-J. Glock \& J. Hyman (Oxford: Wiley-Blackwell, 2017), 547-62.

2017c. Universal Grammar: Wittgenstein versus Chomsky in A Companion to Wittgenstein on Education: Pedagogical Investigations. Eds, M. A. Peters \& J. Stickney (Springer, 2017), 573-600.

2019. 'Wittgenstein's Grammar: Through Thick and Thin' in wittgensteinian (adj.), ed. S, Wuppuluri (Springer).

Pritchard, D.

2012. 'Wittgenstein and the groundlessness of our believing' Synthese 189: 255-72.

2017. 'Wittgenstein on Skepticism' in Blackwell Companion to Wittgenstein, eds H.-J. Glock \& J. Hyman (Oxford: Wiley-Blackwell, 2017), 563-75.

2018. 'Unnatural Doubts' in Skepticism, eds Bruno \& Rutherford (London: Routledge, 2018).

Schönbaumsfeld, G.

2016a. The Illusion of Doubt (Oxford: Oxford University Press). 
2016b. 'Meaning and Conversational Impropriety in Sceptical Contexts Metaphilosophy 47:3, July 2016, 431-48

2017. 'Beliefs-in-a-Vat' Proceedings of the Aristotelian Society 117: 2, July 2017, 141-61.

2019. 'Epistemic angst, intellectual courage and radical scepticism' International Journal for the Study of Skepticism 9:3 (Jul 2019), 206-22.

Travis, C. 2011. 'The Proposition's Progress' in The Oxford Handbook of Wittgenstein, eds O. Kuusela and M. McGinn (Oxford: Oxford University Press), 183-213.

Williams, M. 2017. 'How Hinges Can Be Knowledge' Paper delivered at the Hinge Epistemology Conference, University of California, Irvine, September 9-10, 2017. 